\title{
Dosing of radioactive iodine in end-stage renal disease patient with thyroid cancer
}

\author{
Mallika Bhat', Matty Mozzor², Savneek Chugh³, Vamsi Buddharaju³, Monica Schwarcz' \\ and Guy Valiquette ${ }^{1}$
}

1Division of Endocrinology, Department of Medicine, 2Department of Radiology, and 'Division of Nephrology, New York Medical College, Westchester Medical Center, Valhalla, New York, USA
Correspondence should be addressed to M Schwarcz

Email

monica.schwarcz@ wmchealth.org

\section{Summary}

We describe detailed administration of thyroidal and extrathyroidal doses of radioiodine to a patient with end-stage renal disease on hemodialysis. A thorough description of area under curve measurements in a patient with compromised renal function has rarely been described in the literature. Few publications have described thyroid cancer management of patients on hemodialysis, and we believe our management will aid in patient treatment in the future.

\section{Learning points:}

- Scheduling of hemodialysis is important when administering radioactive iodine.

- Treatment of thyroid cancer with radioiodine in patients with end-stage renal disease requires multidisciplinary approach coordinating dialysis, nuclear medicine and endocrinologists care.

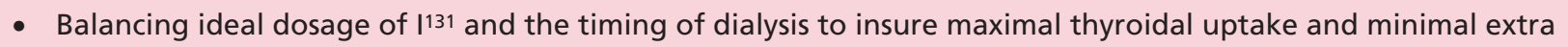

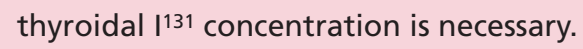

\section{Background}

Radioiodine ablation is the most effective adjuvant treatment after thyroidectomy for certain welldifferentiated thyroid cancers (1). Iodine, as the iodide ion $\left(\mathrm{I}^{-}\right)$is almost entirely absorbed by the thyroid gland, while remaining circulating $\mathrm{I}^{-}$is primarily cleared by the kidney. Therefore, in a patient with end-stage renal disease (ESRD) on dialysis, the administered activity of radioiodine ( $\left.{ }^{131}\right)$ and the timing of dialysis are crucial. There are neither current guidelines nor recommendations for management of thyroid cancer in patients with ESRD (2). We present a case of the use of $\mathrm{I}^{131}$ in the management of thyroid cancer in a patient on hemodialysis.

\section{Case presentation}

A 49-year-old woman with a history of hypertension, ESRD on hemodialysis (HD), goiter and post remote left thyroidectomy presented with compressive symptoms of shortness of breath and difficulty swallowing. Our patient complained of an enlarging right thyroid gland, which had been growing slowly over the past 8 years. Ultrasound revealed a large nodule measuring almost $8 \mathrm{~cm}$ in sagittal plane. Ultrasound-guided fine-needle aspiration was performed, and cytology revealed normal follicular cells.

On physical examination, the patient had a markedly enlarged right thyroid gland, and due to large size of nodule, completion thyroidectomy was recommended. Histopathology revealed a $5.5 \mathrm{~cm}$ classical papillary thyroid cancer with clear surgical margins and without lymphovascular or extrathyroidal invasion. Thyroglobulin measurement prior to surgery was detectable at $3.9 \mathrm{ng} / \mathrm{mL}$. The American Joint Committee on Cancer (AJCC) staging consistent with Stage III T3NO and placing her in the American Thyroid 
Association (ATA) low-to-intermediate risk category (2). The patient's case was reviewed regarding necessity and dose of radioiodine therapy interdepartmentally with consideration of her need for renal transplant and $50 \mathrm{mCi}$ of $\mathrm{I}^{131}$ was subsequently administered. Radioidine was given after levothyroxine withdrawal for 6 weeks. The decision to raise TSH via withdrawal as opposed to thyrogen (recombinant TSH) was discussed interdepartmentally given that recombinant TSH is eliminated significantly slower in dialysis-dependent ESRD patients, resulting in prolonged elevation of TSH levels. A diagnostic pre-scan with I123 was performed and showed residual thyroid tissue, an iodine uptake of $5 \%$ and no evidence of distant metastasis. Our treatment goal was to ablate remaining remnant thyroid tissue and to facilitate follow-up in the future. One week following the diagnostic pre-scan, the patient was administered $50 \mathrm{mCi}(1.85 \mathrm{e}+3 \mathrm{mBq}$ ) (Fig. 1). The patient subsequently received inpatient $\mathrm{HD}$ sessions at 15, 27 and $43 \mathrm{~h}$. The time points were chosen to coincide with the availability of the hemodialysis center and patient transportation. Our patient was discharged once below release criterion of $5 \mathrm{mrem} / \mathrm{h}(0.05 \mathrm{mSv} / \mathrm{h})$ at $1 \mathrm{~m}$. The patient returned 7 days post ablation and received a post-ablation whole body scan (Fig. 2).

Preablation I123 Scan

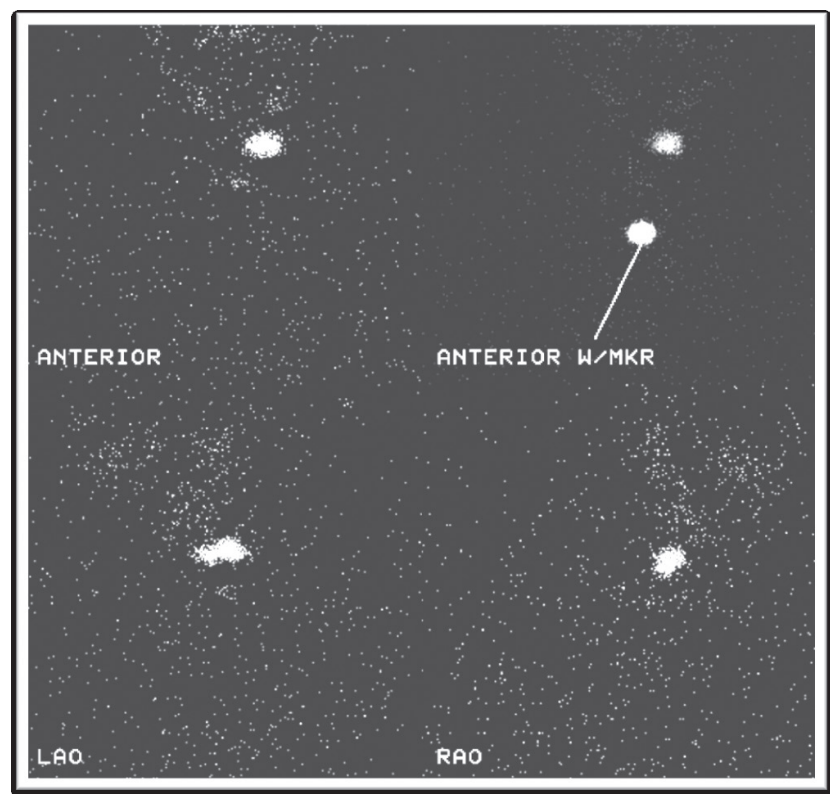

I123 thyroid scan and uptake imaged 24 hours post administration of 8.18 megabecquerel $(\mathrm{mBq})$ of I123 (218 microcuries). lodine uptake to the thyroid remnant is $5 \%$.

Figure 1

1123 thyroid scan and uptake imaged $24 \mathrm{~h}$ post administration of 8.18 megabecquerel $(\mathrm{mBq}$ ) of I-123 (218 microcuries). lodine uptake to the thyroid remnant is $5 \%$.

\section{Investigation}

The effect of any radioactive substance on biological tissues depends on three important properties: the administered activity of the radioisotope, the radiologic half-life of the isotope and the biological half-life in the particular organ for the specific element. Radiologic half-life is the time required for one half of the number of atoms of the particular isotope to undergo physical decay. Biological half-life is the time taken to eliminate one half of the amount of a compound or chemical on a biological basis. The radiological half-life of I-131 is 8.02 days $(3,4)$. The thyroidal biologic half-life of iodide is approximately 80 days, whereas the extrathyroidal biologic half-life of 1131 is 0.33 days $(4,5)$. The effective half-life is the result of the combined actions of physical

A

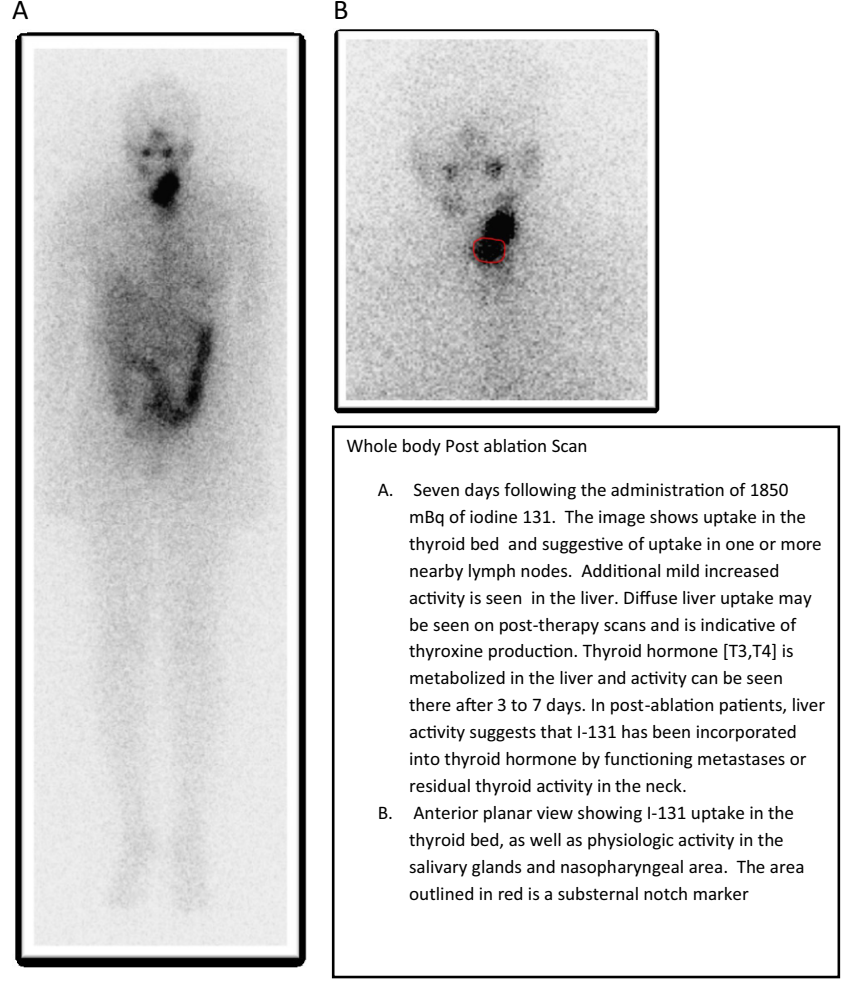

Figure 2

Whole body post-ablation scan. (A) Seven days following the administration of $1850 \mathrm{mBq}$ of 131 . The image shows uptake in the thyroid bed and suggestive of uptake in one or more nearby lymph nodes. Additional mild increased activity is seen in the liver. Diffuse liver uptake may be seen on post-therapy scans and is indicative of thyroxine production. Thyroid hormone $(\mathrm{T} 3, \mathrm{~T} 4)$ is metabolized in the liver and activity can be seen there after 3-7 days. In post-ablation patients, liver activity suggests that $\mathrm{I}-131$ has been incorporated into thyroid hormone by functioning metastases or residual thyroid activity in the neck.

(B) Anterior planar view showing I-131 uptake in the thyroid bed, as well as physiologic activity in the salivary glands and nasopharyngeal area. The area outlined in red is a substernal notch marker. 


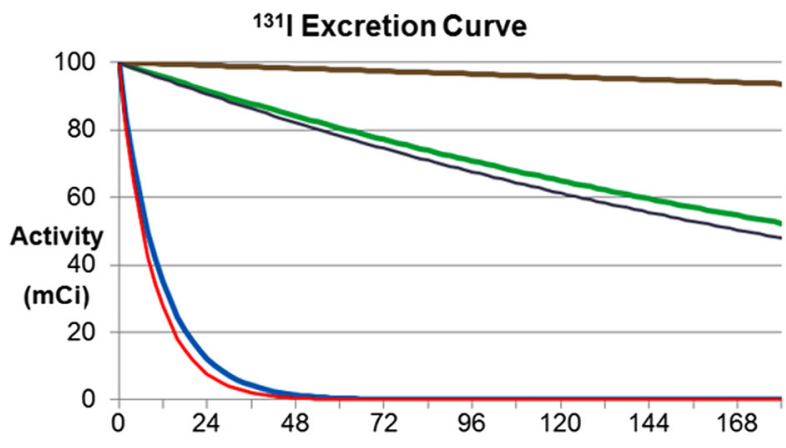

\begin{tabular}{|c|c|}
\hline Half-life $\left(\mathrm{T}_{1 / 2}\right)$ & Days \\
\hline $\begin{array}{c}\text { Thyroidal } \\
\text { Biological }\end{array}$ & 80.0 \\
\hline $\begin{array}{c}\text { Thyroidal } \\
\text { Effective }\end{array}$ & 7.31 \\
\hline $\begin{array}{c}\text { (Physical decay) } \\
\text { Radiological }\end{array}$ & 8.04 \\
\hline $\begin{array}{c}\text { Extrathyroidal } \\
\text { Biological }\end{array}$ & 0.33 \\
\hline $\begin{array}{c}\text { Extrathyroidal } \\
\text { Effective }\end{array}$ & 0.32 \\
\hline
\end{tabular}

\section{Figure 3}

Graph representing the 1131 excretion curve, with the $X$ axis depicting the time in hours and the $Y$ axis depicting the radioactivity. The green curve indicates the physical decay and the blue indicates the extrathyroidal biological half-life. decay and biological elimination (Fig. 3). It is related to the radiologic half-life and the biologic half-life, and it is always the shorter of the shorter of the two half-lives. The formula used $t_{1 / 2 \mathrm{e}}=t_{1 / 2 \mathrm{p}} \times t_{1 / 2 \mathrm{~b}} / t_{1 / 2 \mathrm{p}}+t_{1 / 2 \mathrm{~b}}$ where $t_{1 / 2 \mathrm{e}}$ is the effective half-life, $t_{1 / 2 \mathrm{p}}$ is the physical half-life and $t_{1 / 2 \mathrm{~b}}$ is the biological half-life.

\section{Treatment}

The management challenges of treating the patient were to determine the dosage of $\mathrm{I}^{131}$ and the schedule of the HD. We used the concept of 'Necessary Balancing Act' to formulate the management plan (Fig. 4). The balancing act aims at deciding the ideal dosage of $\mathrm{I}^{131}$ and the timing of dialysis to insure maximal thyroidal uptake and minimal extrathyroidal $\mathrm{I}^{131}$ concentration, thereby maximizing the therapeutic effect and minimizing shortterm and long-term radioactive side effects (1).

The area under the curve (AUC) approach was chosen as it aims for a safe extrathyroidal dose. AUC is the area under the curve in a plot of concentration of drug in blood plasma against time. Typically, the area is computed starting at the time the drug is administered and ending when the concentration in plasma is negligible (5) (Fig. 3). Utilizing our approach, the AUC for a patient with compromised renal function is compared and adjusted to that of a patient with normal renal function.

The aim of our dialysis schedule was to achieve an AUC close to that of a patient with normal renal function. After reviewing previous studies, we devised a schedule of $\mathrm{HD}$ at 15, 27 and $43 \mathrm{~h}$ using a dose of $113150 \mathrm{mCi}$. The schedule deviated from 12, 24 and $48 \mathrm{~h}$ time points to accommodate dialysis coordination (Fig. 5). Plotting of

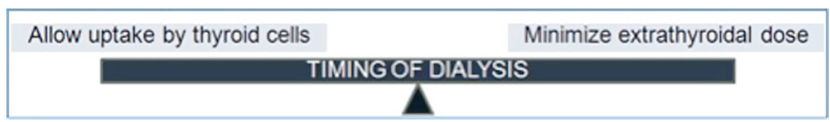

Figure 4

Necessary balancing act in dosing 1131 . the AUC after the treatment revealed an AUC similar to normal renal function (Fig. 6). Since the iodide ion is extremely small compared to the dialysis filtering size, there is no method to either increase or decrease the rate of extra-thyroidal iodine removal by changing the parameters of the dialysis unit. The elimination depends on modality of dialysis and duration of dialysis therapy. Hemodialysis is superior to peritoneal dialysis, and no studies have shown that high efficiency dialysis is superior to low efficiency dialysis (6).

An ion chamber dose rate instrument was used to estimate the amount I131 in the body at any time point. Immediately following the administration of the I131, a dose rate measurement was obtained $1 \mathrm{~m}$ away and directly across from the patient's umbilicus. This dose rate measurement exactly correlates with the administered activity of $50 \mathrm{mCi}$. Subsequent measurements were made at the same position and distance from the patient. The dose rates obtained are directly proportional to the activity remaining in the body at the time the measurement is made.

The thyroidal and the extra-thyroidal doses were estimated to be 360 Gy (target thyroidal dose of 150-500 Gy) and 0.2 Gy, respectively (1). A total-body scan 7 days after treatment confirmed ${ }^{131}$ I uptake at thyroid bed, with no evidence of distant metastases. Biochemical data consisting of thyroglobulin and antithyroglobulin antibody were

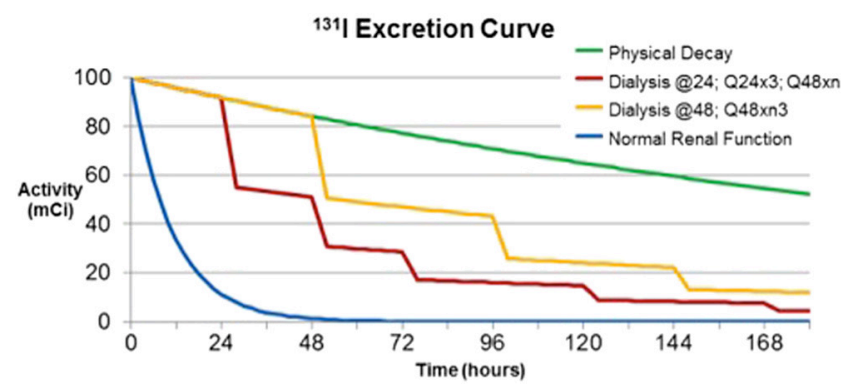

Figure 5

Depicts our attempt to obtain an AUC similar to that in a patient with normal renal function as can be seen below. 


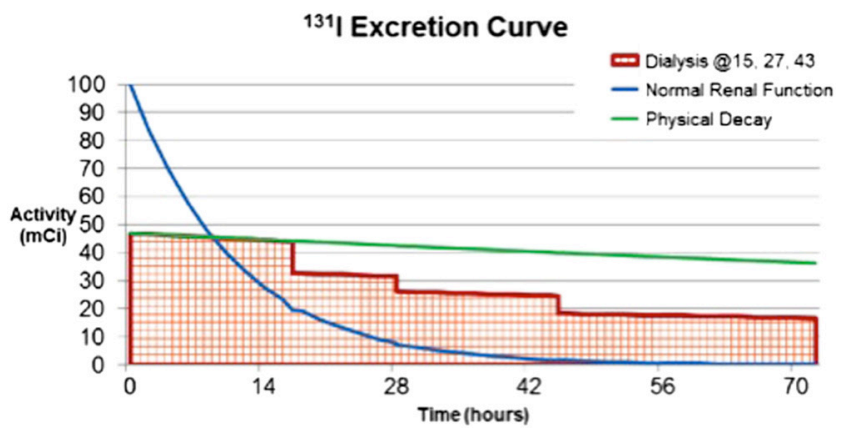

Figure 6

Area under the curve similar to that in a patient with normal renal function.

undetectable at follow-up visits. Ultrasound and an rTSH stimulated I-131 whole body scan performed 5 years later did not reveal residual thyroid tissue in the thyroid bed or any abnormal tissue or uptake throughout the body.

\section{Discussion}

There are conflicting recommendations in the literature regarding changing dose of radioiodine and the timing of dialysis in patients with ESRD and thyroid cancer requiring therapeutic doses of 131I. When compared to a patient with normal renal function, authors Holst, Howard and Daumerie recommend decreasing the dose $(7,8,9)$. In contrast, Jimenez and coworkers and Murcutt recommended using equivalent dosing; while Magne and Morrish increased dosing of I131 in ESRD patients as compared to their normal renal function counterparts $(10,11,12,13)$. In recommending a dose for patients, the timing of hemodialysis is of utmost importance (Table 1). Most of the radioiodine is delivered to the thyroid bed, but in anuric patients, there is an increased risk of exposure to bone marrow, which theoretically would lead to administration of a decreased dose of I131. The greatest reduction in radioiodine was after the first session of hemodialysis as was described in previous case reports, but subsequent hemodialysis reduced patients radioactivity to appropriate levels for discharge.

The ATA guidelines for use of Radioiodine Ablation in Differentiated Thyroid Cancers usually recommends radioiodine remnant ablation all patients with primary size of tumor $>4 \mathrm{~cm}$ due to an increased risk of recurrence. The guidelines also recommend the usage of minimum activity as appropriate if any residual microscopic disease is suspected or documented (2). In addition, although initial fine-needle aspiration of the patient's nodule did not reveal carcinoma, given the large size of her nodule, we believe there may have been sampling error.

I131 is mostly excreted renally and requires consideration of dose delivered to thyroid remnant while minimizing delivery to bone marrow. The dose delivered ultimately also depends on the timing of hemodialysis and the availability of health care providers to coordinate administration of I131 and hemodialysis sessions. Our facility was able to administer I131 after delivery from the pharmacy by the afternoon, explaining why our time points deviate somewhat from 12-, 24and 48-h time points for hemodialysis. This patient was discussed at interdisciplinary rounds and RAI ablation was agreed upon to decrease risk of recurrence and facilitate follow-up. The majority of RAI therapies are performed in the outpatient setting, but patients on hemodialysis patients are unique due to the increased risk of exposure to dialysis staff, decreased clearance

Table 1 Radioiodine dose and timing of dialysis.

\begin{tabular}{|c|c|c|c|}
\hline Study & Dose used $(\mathrm{mCi})$ & Dialysis timing (days after $\mathrm{I}^{131}$ ) & $\begin{array}{l}\text { Recommendations on dose (in comparison to dose } \\
\text { used in patients with normal renal function) }\end{array}$ \\
\hline Holst et al. (7) & 98 & $2,3,4$ & $\begin{array}{l}\text { Use } 21-28 \% \text { of dose and perform dialysis day } \\
2,3 \text { and } 4 \\
\text { Use } 13-16 \% \text { of the dose and perform dialysis } \\
\text { day } 2 \text { and } 4\end{array}$ \\
\hline Bohan et al. (12) & 152 & 2, then thrice weekly & $\begin{array}{l}\text { Decrease the dose for ESRD patients; } \\
\text { no comment on the extent of decrease }\end{array}$ \\
\hline Howard et al. (6) & 20 & 2 & $\begin{array}{l}\text { Reduce the dose by a factor of } 4 \text { and perform } \\
\text { dialysis at } 48 \mathrm{~h}\end{array}$ \\
\hline Daumerie et al. (8) & $\begin{array}{l}25 \text { in } 2 \text { sessions } 6 \text { months } \\
\text { apart }\end{array}$ & $1,2,5,7$ & Use $25 \%$ of the dose and start dialysis at $24 \mathrm{~h}$ \\
\hline Jimenez et al. (9) & 75,87 and 120 in 3 patients & Daily for 5 days & Use same dose \\
\hline Morrish et al. (11) & $\begin{array}{l}50-250 \text { in } 4 \text { sessions over } \\
4.8 \text { years }\end{array}$ & $\begin{array}{l}\text { No comment on timing of } \\
\text { dialysis for first } 2 \text { treatments; } \\
2 \text { days for the } 3 \text { rd treatment }\end{array}$ & Increase the dose \\
\hline Magne et al. (10) & 50 & $1,3,6$ & Increase dose up to $25 \%$ \\
\hline
\end{tabular}


of I131 from the patient and potential contamination of the dialysis machine. In our patient case, proper radiation precautions were facilitated by admitting patient to hospital and performing hemodialysis within a designated patient room followed by appropriate handling of the dialysis machine and tubing. In considering therapies with higher doses of RAI therapy that would be required in setting of metastatic disease, one would again have to maximize administration of therapy to remnant tissue; however, our data do not apply to higher dose RAI therapy. In the future, an outpatient dialysis center with appropriate training and ability to comply with precautions may be feasible for patients requiring I131 therapy.

\section{Patient outcome}

The patient has followed up with endocrinology for 4 years since her radioiodine treatment with no evidence of recurrence of thyroid cancer on both imaging and biochemical examinations. The patient has received a renal transplant one year after her thyroid cancer treatment and remains in excellent health.

\section{Definitions}

\section{Measurement of radioactivity (administered activity)}

Measures the number of events of transformation/decay/ disintegration per unit time.

1 curie $(\mathrm{Ci})=3.7 \times 10^{10}$ decays per second $(1$ bequerel $(\mathrm{Bq})=1$ days $/ \mathrm{s})$.

\section{Measurement of dose}

Gamma constant for I-131: $0.22 \mathrm{mR} / \mathrm{h}$ per $\mathrm{mCi}$ at $1.0 \mathrm{~m}$ (7.647E- $5 \mathrm{mSv} / \mathrm{h}$ per $\mathrm{MBq}$ at $1.0 \mathrm{~m}$.

Different materials absorb different amounts of energy.

Radiation absorbed dose (rad) is a unit of absorbed radiation dose. The SI equivalent unit is the Gray (Gy). $100 \mathrm{rad}=1$ Gray.

Biological effect of radiation depends on the type of ionizing radiation.

Roentgen equivalent in man, or mammal (rem) is a unit of radiation dose equivalent.

Rem $=\mathrm{rad}^{*}$ weighting factor $W_{\mathrm{F}}$.

( $W_{\mathrm{F}}$ is between 1 and 20 ; 1 for $\mathrm{X}$-rays/gamma rays).

The SI equivalent for the REM is the Seivert (Sv).

100 Rem $=1$ Sv.
The equivalent dose is the dose to the whole body calculated by summing the dose to specific tissues times their tissue weighting factors. The tissue weighting factor for thyroid is 0.05 and for bone marrow is 0.12 . These are the two most significant tissues in this case.

\section{Declaration of interest}

There is no conflict of interest that could be perceived as prejudicing the impartiality of the research reported.

\section{Funding}

This research did not receive any specific grant from any funding agency in the public, commercial or not-for profit sector.

\section{Patient consent}

Patient consent has been obtained from the patient for publication of the submitted article and accompanying images.

Author contribution statement

All authors contributed equally to the care of the patient and the writing of this report.

\section{References}

1 Silberstein EB, Alavi A, Balon HR, Clarke SE, Divgi C, Gelfand MJ, Goldsmith SJ, Jadvar H, Marcus CS, Martin WH, et al. 2012 The SNMMI practice guideline for therapy of thyroid disease with 131I 3.0. Journal of Nuclear Medicine 53 1633-1651. (doi:10.2967/ jnumed.112.105148)

2 Haugen BR, Alexander EK, Bible KC, Doherty GM, Mandel SJ, Nikiforov YE, Pacini F, Randolph GW, Sawka AM, Schlumberger M, et al. 20162015 American Thyroid Association Management Guidelines for adult patients with thyroid nodules and differentiated thyroid cancer: the American Thyroid Association Guidelines task force on thyroid nodules and differentiated thyroid cancer. Thyroid 26 1-133. (doi:10.1089/thy.2015.0020)

3 Snyder WS, Ford MR, Warner GG \& Watson SB 1975 Absorbed dose per unit cumulated activity for selected radionuclides and organs (part 1). Society of Nuclear Medicine MIRD Pamphlet \#11.

4 Snyder W, Ford M, Warner G \& Watson S 1975 Absorbed dose per unit cumulated activity for selected radionuclides and organs (part 2). Society of Nuclear Medicine MIRD Pamphlet \#11.

5 Snyder W, Ford M, Warner G \& Watson S 1975 Absorbed dose per unit cumulated activity for selected radionuclides and organs. Society of Nuclear Medicine MIRD Pamphlet \#11:Part 1.

6 Kaptein E, Levenson M, Siegel M, Gadallah M \& Akmal M 2000 Radioiodine dosimetry in patients with end stage renal disease receiving continuous ambulatory peritoneal dialysis therapy. Journal of Clinical Endocrinology and Metabolism 85 3058-3064.

7 Howard N \& Glasser M 1981 Iodine 131 ablation therapy for a patient on maintenance haemodialysis. British Journal of Radiology 54 259. (doi:10.1259/0007-1285-54-639-259)

8 Holst JP, Burman KD, Atkins F, Umans JG \& Jonklaas J 2005 Radioiodine therapy for thyroid cancer and hyperthyroidism in 
patients with end-stage renal disease on hemodialysis. Thyroid $\mathbf{1 5}$ 1321-1331. (doi:10.1089/thy.2005.15.1321)

9 Daumerie C, Vynckier S, Caussin J, Jadoul M, Squifflet JP, de Patoul N \& Wambersie A 1996 Radioiodine treatment of thyroid carcinoma in patients on maintenance hemodialysis. Thyroid 6 301-304. (doi:10.1089/thy.1996.6.301)

10 Jimenez RG, Moreno AS, Gonzalez EN, Simón FJL, Rodriguez JR, Jimenez JC, Córdoba MH, Albertino RV \& Jimenez RA 2001 Iodine-131 treatment of thyroid papillary carcinoma in patients undergoing dialysis for chronic renal failure: a dosimetric method. Thyroid 11 1031-1034. (doi:10.1089/ 105072501753271716)
11 Magne N, Magne J, Bracco J \& Bussiere F 2002 Disposition of radioiodine (131)I therapy for thyroid carcinoma in a patient with severely impaired renal function on chronic dialysis: a case report. Japanese Journal of Clinical Oncology 32 202-205. (doi:10.1093/jjco/hyf049)

12 Morrish DW, Filipow LJ, McEwan AJ, Schmidt R, Murland KR, von Westarp C \& Betcher KB 1990 131I treatment of thyroid papillary carcinoma in a patient with renal failure. Cancer $\mathbf{6 6}$ 2509-2513. (doi:10.1002/1097-0142(19901215)66:12<2509::AIDCNCR2820661211>3.0.CO;2-M)

13 Murcutt G, Edwards J, Boakye J \& Davenport A 2008 Hemodialysis of chronic kidney failure patients requiring ablative radioiodine therapy. Kidney International 73 1316-1319. (doi:10.1038/ki.2008.95)

Received in final form 12 October 2017

Accepted 23 October 2017 